\title{
Decreased haem oxygenase-1 and increased inducible nitric oxide synthase in the lung of severe COPD patients
}

\author{
P. Maestrelli*, C. Páska*, M. Saetta\#, G. Turato\#, Y. Nowicki*, S. Monti", B. Formichi", \\ M. Miniati ${ }^{\top}$, L.M. Fabbri ${ }^{+}$
}

Decreased haem oxygenase-1 and increased inducible nitric oxide synthase in the lung of severe COPD patients. P. Maestrelli, C. Páska, M. Saetta, G. Turato, Y. Nowicki, S. Monti, B. Formichi, M. Miniati, L.M. Fabbri. C) ERS Journals Ltd 2003.

ABSTRACT: Oxidant/antioxidant imbalance is implicated in the pathogenesis of chronic obstructive pulmonary disease (COPD).

The current study examined the expression of antioxidant and pro-oxidant enzymes, haem oxygenases (HO) and inducible nitric oxide synthase (iNOS) respectively, in patients with severe COPD and control smokers without lung function impairment. Immunoreactivity for HO-1, HO-2, iNOS and nitric oxide-derived oxidants expressed as nitrotyrosine (N-Tyr) was quantified in peripheral lung.

HO-1+ alveolar macrophages were decreased in severe COPD compared to control smokers, whereas no difference was observed in iNOS+ macrophages. In contrast, severe patients had significantly higher numbers of iNOS + cells in alveolar walls. These iNOS + cells were identified as type 2 pneumocytes and their number was inversely related to HO-1+ macrophages. There were no significant differences in N-Tyr immunostaining between the two groups. However, the rate of protein nitration in lung tissue was directly related to iNOS expression and associated with lower values of forced expiratory volume in one second/forced vital capacity. HO-2 was constitutively expressed by type 2 pneumocytes and these cells were increased in severe COPD.

In conclusion, the results suggest that the enzymes involved in the oxidative stress response may have a different role in the lung defence and that imbalance between haem oxygenase-1 and inducible nitric oxide synthase may be associated with the development of severe impairment in chronic obstructive pulmonary disease patients.

Eur Respir J 2003; 21: 971-976.
*Dept of Environmental Medicine and Public Health, ${ }^{\#}$ Dept of Clinical and Experimental Medicine, Section of Respiratory Diseases University of Padova, Padua, "CNR Institute of Clinical Physiology, Pisa, and ${ }^{+}$Dept of Medical Oncological and Radiological Sciences, Section of Respiratory Diseases, University of Modena and Reggio Emilia, Modena, Italy.

Correspondence: P. Maestrelli, Dipartimento di Medicina Ambientale e Sanitá Pubblica, Università degli Studi di Padova, via Giustiniani,2, 35128 Padova, Italy.

Fax: 390498212566

E-mail: piero.maestrelli@unipd.it

Keywords: Cigarette smoke immunohistochemistry

inflammation

macrophages

oxidative stress

Received: October 252002

Accepted after revision: February 282003

Supported by the Italian Ministry of University and Research, the University of Padova and ARCA.
Oxidant/antioxidant imbalance has been implicated in the pathogenesis of chronic obstructive pulmonary disease (COPD) [1]. Exogenous oxidants are contained in cigarette smoke, the major risk factor for COPD, and are produced by the inflammatory cells that characterise the pathology of COPD [2]. Oxidative stress induces a cascade signalling mechanism, which activates transcription factors leading to upregulation of genes coding for pro-inflammatory and antiinflammatory cytokines and enzymes [1]. This study focuses on two of these enzymes, haem oxygenase (HO) and inducible nitric oxide synthase (iNOS). The three isoforms of $\mathrm{HO}$, inducible $\mathrm{HO}-1$, constitutive $\mathrm{HO}-2$ and HO-3, catalyse the degradation of haem to biliverdin, which is then reduced to bilirubin, producing free iron and carbon monoxide (CO) [3-4]. HO has been suggested to have important antioxidant capacity and significance in protecting lung cells against oxidant exposure. HO-1 was demonstrated to be induced by a variety of injurious stimuli, including reactive oxygen species (ROS) [3]. In an earlier study, the present authors showed that chronic smokers exhibit increased expression of HO-1 in alveolar spaces and HO-2 in alveolar walls of the lung [5].

Nitric oxide (NO) synthase may play a role in the pathogenesis and progression of COPD, since NO has direct toxic effects and also reacts with superoxide and generates toxic peroxynitrite in the cells [6]. Some studies found that iNOS was more expressed in interstitial lung disease [7]. The role of this enzyme in the pathogenesis and progression of COPD is controversial [8,9]. In addition, most studies examined iNOS and its products in induced sputum, while it is believed that the peripheral airways are the major site of airflow limitation in COPD. Investigating the mechanisms involved in the progression of COPD may prove useful in the identification of subgroups of subjects prone to rapid decline in lung function and targeting therapeutic intervention.

The current study analysed the expression of enzymes with antioxidant properties, as $\mathrm{HO}-1$ and $\mathrm{HO}-2$, and prooxidant properties, as iNOS, in the peripheral lung of patients with COPD and severe impairment of lung function in comparison to subjects with comparable smoking history, but with no impairment of lung function. The involvement of NO-derived oxidants was evaluated by immunostaining of nitrotyrosine adducts to proteins. The immunoreactivity of $\mathrm{HO}$, iNOS and nitrotyrosine was quantified in alveolar macrophages and in alveolar walls, and the results were correlated with indexes of lung function. 


\section{Methods}

\section{Subjects}

Two groups of subjects undergoing lung resection for solitary peripheral carcinoma or lung-volume reduction surgery (LVRS) for emphysema were examined: 11 subjects with a smoking history of $>20$ pack-yrs and severe fixed airway obstruction (severe COPD) and 13 subjects with a smoking history of $>20$ pack-yrs and normal lung function, i.e. forced expiratory volume in one second (FEV1)/vital capacity (VC) more than the predicted value minus 1.64 residual SD (control smokers) [10]. Severe airway obstruction was defined as a FEV1/VC less than the predicted value minus 1.64 residual SD and FEV1 $<50 \%$ pred [11]. Nine of the tissue samples out of 11 in the severe COPD group were from patients undergoing LVRS, while the remaining samples were obtained from surgery for cancer.

All subjects exhibited an increase in FEV1 after inhalation of $200 \mu \mathrm{g}$ of salbutamol $<15 \%$ compared with baseline value. The subjects had had no exacerbations, had been free of acute upper respiratory tract infections, and had not received glucocorticoids or antibiotics within the month preceding surgery. They had negative skin tests for common allergen extracts and no past history of asthma or allergic rhinitis. The study conformed to the Declaration of Helsinki, and informed written consent was obtained for each subject.

\section{Pulmonary function tests}

Pulmonary function tests were obtained within a week before surgery, and included spirometry, arterial blood gas analysis, and CO diffusing capacity [12]. Diffusing capacity was not measured in two patients in the severe COPD group and in five control smokers.

\section{Immunohistochemistry}

Tissue blocks were taken from the subpleural parenchyma, avoiding areas involved by tumour, fixed and embedded in paraffin as described elsewhere [13]. HO-1 and HO-2 proteins were detected by immunohistochemisty using mouse monoclonal antibody against HO-1 (anti-HO-1; Transduction Lab, Lexington, KY, USA) and goat polyclonal antibody against HO-2 (C-20, sc-7697; Santa Cruz Biotechnology, Inc., Santa Cruz, CA, USA), with the alkaline phosphatase-antialkaline phosphatase (APAAP) method (Dako Ltd, High Wycombe, UK) or streptavidin biotinylated alkaline phosphatase complex (StreptABComplex/AP; Dako Ltd), respectively. Monoclonal antibody against iNOS (sc7271; Santa Cruz Biotechnology, Inc.) was processed with Envision+TM (K4000, Dako Ltd) method and diamino benzydine (DAB) staining. Negative controls for nonspecific binding incubated with secondary antibodies only were processed and revealed no signal. 3-Nitrotyrosine immunostaining (N-Tyr) was performed using rabbit polyclonal antibody (anti 3-Nitrotyrosine; Upstate Biotech, Lake Placid, NY, USA), followed by peroxidase conjugated swine antibodies (P399; Dako Ltd) and DAB. Positive controls were processed incubating slides with $1 \mathrm{mM} \mathrm{NaNO} 2$ and $1 \mathrm{mM} \mathrm{H} \mathrm{H}_{2}$ in $100 \mathrm{mM}$ acetate buffer before exposure to primary antibody. Negative controls were processed incubating primary antibody with $1 \mathrm{mM}$ nitrotyrosine before use.

Immunostaining was examined in bronchial epithelium, pulmonary vessels, alveolar walls and alveolar macrophages using light microscopy (Zeiss, Oberkochen, Germany) at
$40 \times$ magnification in blind fashion. HO-1, HO-2, iNOS and $\mathrm{N}$-Tyr staining was quantified in alveolar macrophages and in cells of the alveolar wall, as described elsewhere [5]. Briefly, at least 20 high-power fields of lung parenchyma were randomly selected for each section and at least 100 macrophages inside alveoli were evaluated. The number of positively stained cells within the alveolar walls was computed using a light microscope (Leica DMLB; Leica, Cambridge, UK), connected to a video recorder which was linked to a computerised image system.

Double immunostaining was performed in order to determine the cell type staining positively for $\mathrm{HO}-1, \mathrm{HO}-2$ and iNOS. CD68 (macrophages) and surfactant protein (SP)-B (type 2 pneumocytes)-positive cells were studied. Slides were double stained with antibodies anti-CD68 (goat polyclonal sc-7083, Santa Cruz Biotechnology, Heidelberg, Germany or mouse monoclonal M814, Dako Ltd) or anti-SP-B (polyclonal rabbit antibody gift of A. Baritussio, University of Padova, Italy) [14] and anti-HO-1, anti-HO-2 or anti-iNOS [5]. Control slides were obtained by performing double staining in which one of the primary antibodies was not added.

\section{Statistical analysis}

Differences between variables in table 1 were analysed using an unpaired t-test. The Mann-Whitney U-test was used to compare histological findings between the two groups because these variables were not normally distributed. Correlation coefficients were calculated using Spearman's rank method. At least three replicate measurements of immunostained slides were performed by the same observer in at least 10 randomly selected slides to assess the intraobserver reproducibility [15]. Intraclass correlation coefficients were between 0.90 and 0.78 . Probability values of $\mathrm{p}<0.05$ were accepted as significant.

\section{Results}

Table 1 shows the characteristics of the subjects examined. The two groups of subjects were similar with regard to age and smoking history. Severe COPD exhibited lower values of arterial oxygen tension $(\mathrm{p}<0.001), \mathrm{CO}$ diffusing capacity $(p<0.001)$ and diffusion coefficient $(p<0.01)$. According to the Global initiative for Chronic Obstructive Lung Disease

Table 1. - Subject characteristics

\begin{tabular}{|c|c|c|}
\hline & Severe COPD & Control smokers \\
\hline Subjects M:F & $8: 3$ & $12: 1$ \\
\hline Age yrs & $64 \pm 3$ & $65 \pm 3$ \\
\hline \multicolumn{3}{|l|}{ Smoking history } \\
\hline Pack-yrs & $46 \pm 8$ & $43 \pm 5$ \\
\hline Exsmokers $\mathrm{n}$ & 4 & 1 \\
\hline FEV1 $\%$ pred & $32 \pm 3$ & $98 \pm 4$ \\
\hline FEV1/FVC \% & $36 \pm 3$ & $75 \pm 2$ \\
\hline $\mathrm{Pa}, \mathrm{O}_{2} \mathrm{mmHg}$ & $66 \pm 4$ & $87 \pm 2 * *$ \\
\hline 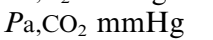 & $44 \pm 4$ & $38 \pm 1$ \\
\hline$K \mathrm{CO} \%$ pred & $40 \pm 7$ & $77 \pm 10 *$ \\
\hline$D \mathrm{~L}, \mathrm{CO} \%$ pred & $41 \pm 6$ & $81 \pm 4 * *$ \\
\hline
\end{tabular}

Values are expressed as mean \pm SEM. COPD: chronic obstructive pulmonary disease; M: male; F: female; FEV1: forced expiratory volume in one second; $\%$ pred: $\%$ predicted; FVC: forced vital capacity; $\mathrm{Pa}, \mathrm{O}_{2}$ : arterial oxygen tension; $\mathrm{Pa}, \mathrm{CO}_{2}$ : carbon dioxide arterial tension; $K C O$ : carbon monoxide transfer coefficient; $D \mathrm{~L}, \mathrm{CO}$ : $\mathrm{CO}$ diffusing capacity. ${ }^{*}: \mathrm{p}<0.01{ }^{* *}: \mathrm{p}<0.001$ compared with severe COPD 

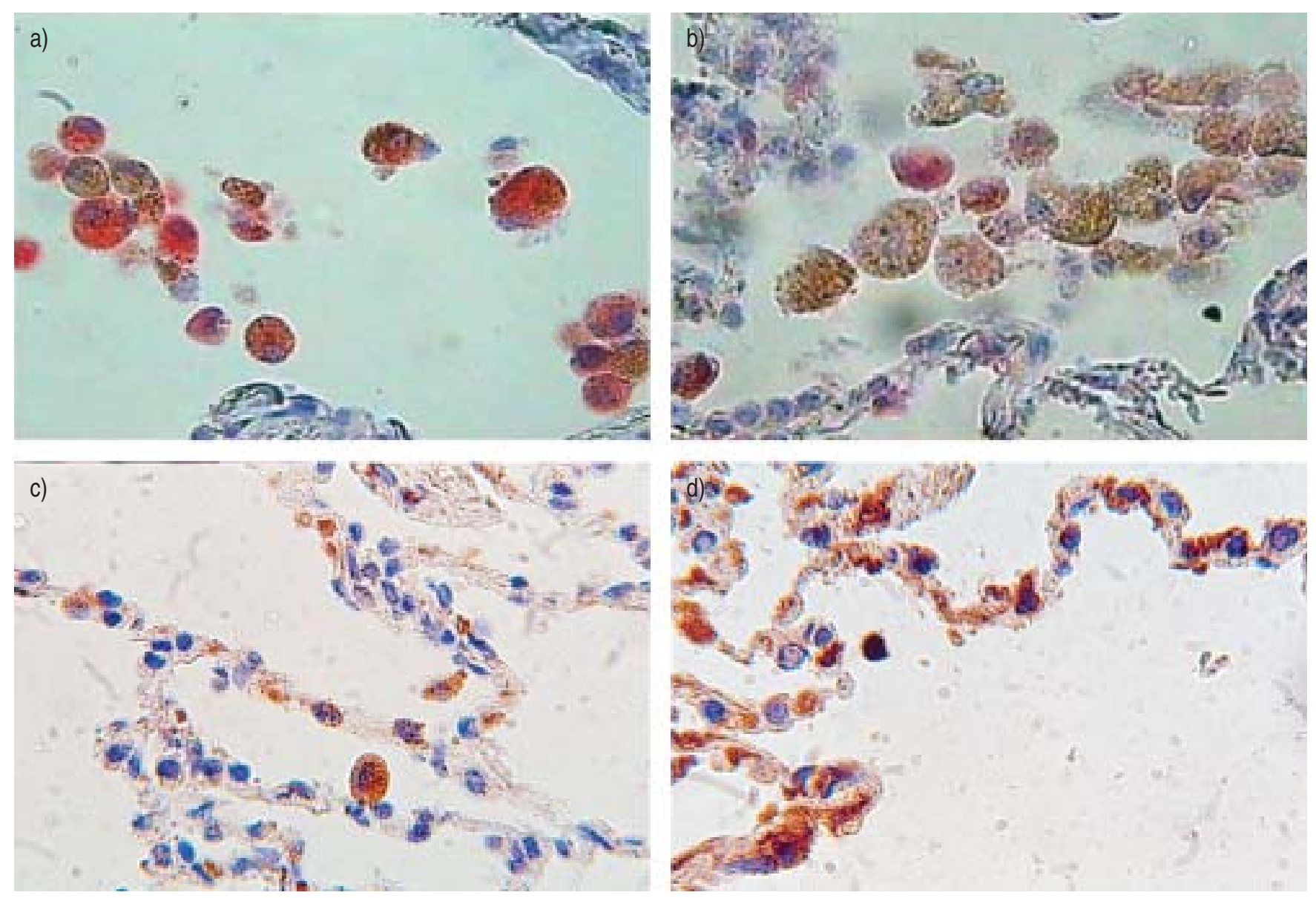

Fig. 1.- Immunohistochemistry study of human lung surgical specimens. a) Alveolar spaces stained for haem oxygenase (HO)-1 in a control smoker. b) Alveolar spaces stained for HO-1 in a severe chronic obstructive pulmonary disease (COPD) patient. c) Alveolar wall stained for inducible nitric oxide synthase (iNOS) in a control smoker. d) Alveolar wall stained for iNOS in a severe COPD subject. Formalin-fixed paraffin-embedded sections were processed for immunohistochemistry using antihuman HO-1 antibody and alkaline phosphatase-anti-alkaline phosphatase (APAAP) method developed with fast red $(a, b)$ or antihuman iNOS antibodies and Envision secondary antibodies conjugated with peroxidase developed with diamino benzydine (c, d). All sections are counterstained with haematoxylin.

(GOLD) classification [16], in the group of severe COPD six patients were in stage IIB and five patients in stage III.

The counts of alveolar macrophages in severe COPD (median 154 (interquartile range 143-174)) were not significantly different from those in control smokers (157 (142204)). The majority of cells in alveolar spaces counted as alveolar macrophages were CD68-positive (70.2\% (55.4-83.8)). HO-1 immunostaining was observed mainly in cells of alveolar spaces, whereas it was negative in bronchial epithelium and vessels (fig. 1). Most of the HO-1-positive cells in alveolar spaces were CD68-positive (82.6\% (72.4-88.9)). The percentage of HO-1-positive alveolar macrophages was significantly lower in subjects with severe COPD (26.0\% (12.3-32.6)) compared with control smokers (44.1\% (34.7-57.5); $\mathrm{p}<0.01$; table 2, fig. 2). The percentages of iNOS+ (fig. 2) and N-Tyr+ macrophages were not different between the two groups (table 2).

Immunostaining for HO-2 was present in alveolar macrophages, in the alveolar wall, in smooth muscle and in cells of adventitia of pulmonary arteries, and in a few cells of bronchial wall. Percentages of HO-2 immunostaining of alveolar macrophages were similar in the two groups (COPD $75.4 \%$ (54.2-88.1) versus controls 67.9\% (35.9-75.6)). The number of HO-2-positive cells in the alveolar wall was significantly higher $(\mathrm{p}<0.01)$ in severe COPD (18.0 cells $\left.\cdot \mathrm{mm}^{-1}(12.7-22.8)\right)$ compared to control smokers (11.3 cells $\left.\cdot \mathrm{mm}^{-1}(10.6-12.2)\right)$ (table 3, fig. 3). Double immunostaining indicated that the
HO-2-positive cells in the alveolar wall were type 2 pneumocytes (92.3\% (88.6-93.9)). Conversely, 97\% (93-98\%) of type 2 pneumocytes were HO-2-positive.

iNOS staining was present in the alveolar wall and alveolar macrophages, in smooth muscle, in adventitia of pulmonary arteries and bronchial wall. The number of iNOS-positive cells in the alveolar wall was significantly increased in severe COPD (13.9 cells $\left.\cdot \mathrm{mm}^{-1}(11.4-19.2)\right)$ with respect of control smokers (4.2 cells $\cdot \mathrm{mm}^{-1}(2.3-5.9) ; \mathrm{p}<0.001$; table 3 , fig. 3$)$. By double immunostaining, most of iNOS-positive cells showed immunoreactivity for SP-B (85.7\% (63.9-87.8)), indicating

Table 2.-Comparison of alveolar macrophages per highpower field (hpf) and percentages of haem oxygenase (HO)$1-$, inducible nitric oxide synthase (iNOS)- and nitro-tyrosine ( $\mathrm{N}$-Tyr)-positive alveolar macrophages in the two groups of subjects

\begin{tabular}{lcc}
\hline & Severe COPD & Control smokers \\
\hline Macrophages $\cdot \mathrm{hpf}^{-1} \mathrm{n}$ & $4.4(3.1-4.9)$ & $4.2(3.1-5.8)$ \\
HO-1+ macrophages \% & $26.0^{*}(12.3-32.6)$ & $44.1(34.7-57.5)$ \\
iNOS+ macrophages \% & $52.1(28.1-75.3)$ & $50.9(41.4-53.8)$ \\
N-Tyr+ macrophages \% & $66.2(34.7-78.1)$ & $65.0(46.9-78.7)$ \\
\hline
\end{tabular}

Values are expressed as medians (interquartile range). COPD: chronic obstructive pulmonary disease. $*$ : $\mathrm{p}<0.01$ versus control smokers. 


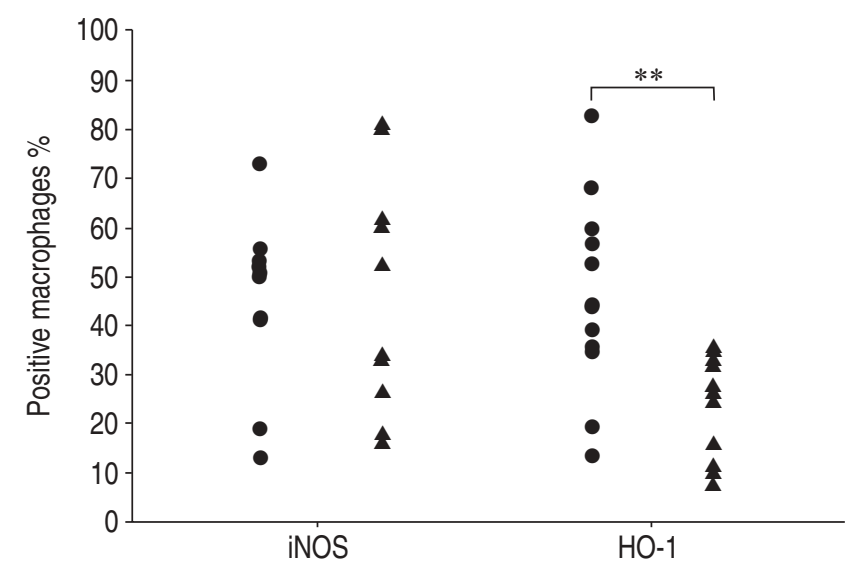

Fig. 2.-Comparison of individual values of inducible nitric oxide synthase (iNOS) and haem oxygenase (HO)-1-positive alveolar macrophages between control smokers (O) and severe chronic obstructive pulmonary disease $(\boldsymbol{\Delta}){ }^{* *}: \mathrm{p}<0.01$.

Table 3. - Comparison of haem oxygenase (HO)-2-, inducible nitric oxide synthase (iNOS)- and nitrotyrosine (NTyr)-positive cells in the alveolar wall in the two groups of subjects

\begin{tabular}{lcc}
\hline & Severe COPD & Control smokers \\
\hline $\begin{array}{c}\mathrm{HO}-2+\text { cells } \cdot \mathrm{mm}^{-1} \\
\text { of alveolar wall }\end{array}$ & $18.0^{*}(12.7-22.8)$ & $11.3(10.6-12.2)$ \\
$\begin{array}{c}\text { iNOS+ cells } \cdot \mathrm{mm}^{-1} \\
\text { of alveolar wall } \\
\begin{array}{c}\mathrm{N}-\mathrm{Tyr}+\text { cells } \cdot \mathrm{mm}^{-1} \\
\text { of alveolar wall }\end{array}\end{array}$ & $13.9^{* *}(11.4-19.2)$ & $4.2(2.3-5.9)$ \\
\hline
\end{tabular}

Values are expressed as medians (interquartile range). COPD: chronic obstructive pulmonary disease. ${ }^{*}: \mathrm{p}<0.01 ; * *: \mathrm{p}<0.001$ versus control smokers.

that they were type 2 pneumocytes. The extent of N-Tyr staining in alveolar wall tended to be greater in severe COPD than in control smokers, but the difference was not statistically significant ( $\mathrm{p}=0.07$, table 3 ). Considering the two groups together, there was a positive, linear correlation between immunoreactivity for iNOS and N-Tyr in alveolar walls $(\mathrm{rho}=0.54, \mathrm{p}<0.05)$. A similar relationship was observed between iNOS + macrophages and N-Tyr + macrophages (rho $=0.41$, $\mathrm{p}=0.06$ ). iNOS + cells in alveolar wall were inversely related to $\mathrm{HO}-1$-positive macrophages ( $r h o=-0.44, \mathrm{p}<0.05$ ).

Immunostaining for $\mathrm{N}-\mathrm{Tyr}$ in alveolar wall inversely correlated with FEV1/forced vital capacity (FVC) ( $\mathrm{rho}=-0.62$, $\mathrm{p}=0.05$ ) in control smokers and showed the same trend in the group of severe COPD (rho=-0.60, $\mathrm{p}=0.07$ ). No significant relationships were detected between immunostaining for HO-1, HO-2, iNOS, and lung function parameters or smoking history in the two groups of patients.

\section{Discussion}

The present study found that in severe COPD there was a reduced expression of HO-1 in alveolar macrophages, whereas the numbers of type 2 pneumocytes expressing iNOS and HO-2 was increased. The rate of protein nitration in the lung tissue was directly related with the expression of iNOS and was associated with lower values of FEV1/FVC ratio.

Oxidative stress and imbalance of host defence mechanisms have been implicated in the pathogenesis of COPD [1].

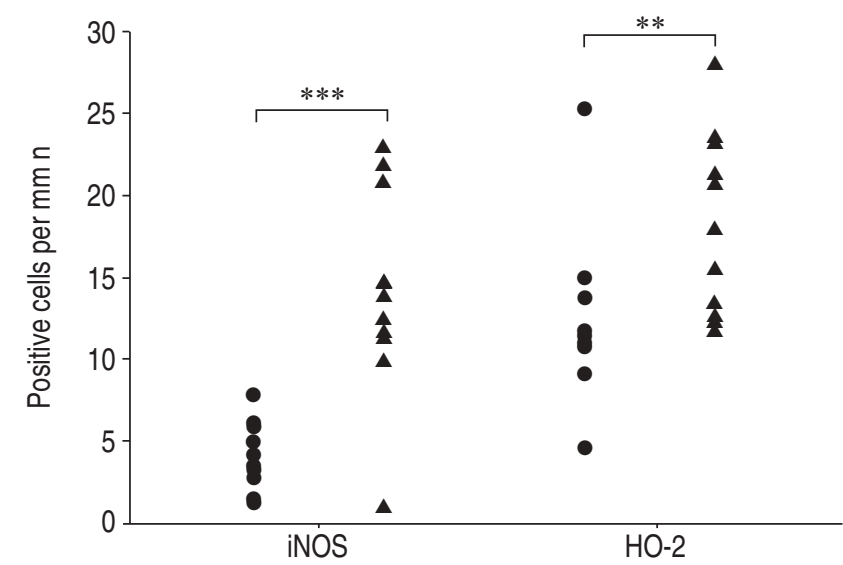

Fig. 3.-Comparison of individual values of inducible nitric oxide synthase (iNOS) and haem oxygenase (HO)-2-positive cells in alveolar wall between control smokers (O) and severe chronic obstructive pulmonary disease $(\boldsymbol{\Delta}){ }^{* *}: \mathrm{p}<0.01 ; * * *: \mathrm{p}<0.001$.

Oxidants, either inhaled or produced by inflammatory cells, induce inflammatory responses in the lung via signalling mechanisms. Redox-sensitive transcription factors, such as nuclear factor- $\kappa \mathrm{B}$ and activator protein 1 , have been shown to be activated in epithelial cells and inflammatory cells during oxidative stress, leading to upregulation of a number of anti- and pro-inflammatory genes, including those coding for HO-1 and iNOS [1]. The functional significance of induction of HO-1 and iNOS is not well understood, as their activity can result in either protection or injury depending on experimental setting [17, 18].

Excessive production of NO via iNOS can cause adverse effects in lung tissue by reactions with superoxide anion and oxygen, leading to development of reactive nitrogen species [19]. Through its products $\mathrm{CO}$, iron and bilirubin, $\mathrm{HO}$ is believed to have a role in cytoprotection against oxidant injury [3]. The two HO, HO-1 and HO-2, have differential roles and can only partially replace each other [20]. In a previous study, the present authors found a different localisation of the two isoforms in the lung of healthy subjects and smokers, with HO-1 predominating in macrophages and HO-2 in lung parenchyma, particularly in type 2 pneumocytes [5]. A similar distribution of HO-1 and HO-2 was detected in severe COPD patients, indicating that progression of inflammatory process and remodelling do not alter the localisation of these enzymes.

Expression of HO-1 was most prominent in alveolar macrophages of patients with sarcoidosis and interstitial pneumonia, whereas HO-1 immunoreactivity was not detectable or was very low in bronchiolar epithelium, alveolar epithelium and endothelium [21]. This is in agreement with the HO-1 localisation in the samples of peripheral lung in the present study and contrasts with the finding of HO-1-positive bronchial epithelial cells in larger airways in asthma [22]. Taken together, these observations suggest that expression of HO-1 in bronchial epithelial cells is dependent on the site of the bronchial tree examined.

The current authors previously showed that HO-1 and HO2 expression was increased in smokers compared with nonsmokers, but no differences were found between healthy smokers and smokers with mild COPD [5]. By studying more severe COPD patients, including those with a high degree of parenchymal destruction, the current authors observed decreased HO-1 expression in alveolar macrophages and increased number of $\mathrm{HO}-2+$ type 2 pneumocytes. As recently described, HO-1 gene promoter polymorphisms may reduce 
the inducibility of HO-1 by ROS [23], thereby resulting in different susceptibility to damage by cigarette smoke. The current findings confirm a relationship between HO-1 diminution and COPD severity. While smokers exhibited higher HO-1 levels, with respect to nonsmokers, thereby suggesting active defence mechanisms against smoke injury, patients with severe COPD may have an impaired defence against oxidative stress, although their smoking history was not different from control smokers. Altered expression of HO might also be a consequence of the disease. Since HO-2 is a constitutive enzyme and as a result is expressed in alveolar wall exclusively by type 2 pneumocytes, its increase may reflect the increase in number of these cells in the lung. In fact, lung cell proliferation may be induced by cigarette smoke and, in spite of destructive process, alveolar wall thickening may be detected in severe COPD [24, 25]. The role of the constitutive form of $\mathrm{HO}$ in the lung remains undetermined. Based on the present authors' results, HO-2 could prevent excessive protein nitration favoured by iNOS products.

This is the first study on iNOS in peripheral lung tissue of patients with COPD. The expression of iNOS in human lung has been documented previously in normal airway epithelium, asthma, interstitial pneumonias and granulomatous lung diseases [7, 26-28]. The current study's results on immunoreactivity for iNOS are consistent with previous reports that show a wide distribution of the enzyme in lung cells, including epithelial, vascular and inflammatory cells [29, 30]. By examining alveolar macrophages, the current study confirms previous findings of similar expression of iNOS in sputum macrophages in subjects with COPD and healthy subjects $[8,9]$. However, in the parenchymal compartment of the lung, the current study detected higher iNOS expression in type 2 pneumocytes of severe COPD. This compartmentalisation of iNOS in human lung is in agreement with observations made in rats [31]. Rat type 2 pneumocytes expressed iNOS and released similar levels of $\mathrm{NO}$ as alveolar macrophages, although macrophages are generally considered the primary cellular mediator of host defence. The current results are consistent with the hypothesis that type 2 pneumocytes play a role as the first line of defence, together with epithelium and macrophages, against lung injury [32], and that their function may be critical for the lung tissue being destroyed by emphysema [33].

Excess of NO, produced by iNOS, in the presence of superoxide anion promotes nitration of tyrosine residues on proteins. Tyrosine nitration is heavily dependent on both the concentration of $\mathrm{NO}$ and the molecular environment [19]. Data on the role of iNOS products, as NO, are rather contradictory in the literature. Higher, lower or similar levels of exhaled NO have been shown in COPD subjects compared with controls and either positive or negative correlations of exhaled NO with FEV1 have been reported [8, 34, 35]. Nitrotyrosine-positive cells were more frequent in sputum of COPD patients in respect of healthy controls [8]. The present authors were able to confirm the latter finding in the alveolar wall, but not in alveolar macrophages in severe COPD. In addition, the present authors' data suggest that nitration of proteins in lung tissue may have an adverse effect on lung function. The substantial differences between the two studies make it difficult to compare the results. In fact, the severity of COPD was milder in the study of ICHINOSE et al. [8] and the compartment of respiratory tract examined was different. Moreover, immunohistochemical technique is not suitable for accurate quantitative evaluation of nitrated proteins.

The inverse relationship between HO-1 and iNOS in the lung might be explained by regulatory interaction between the two enzymes. HO is able to downregulate iNOS by degrading haem, a component of the enzyme, and by the inhibitory action of $\mathrm{CO}$ [36]. A reduction of HO-1 may increase haem availability for synthesis and optimal activity of iNOS and enhance formation of pro-oxidant byproducts, that is, NO derived from iNOS activation. Conversely, a stabilising effect of NO on HO-1 messenger ribonucleic acid has been shown in vitro [37], which would upregulate $\mathrm{HO}-1$. In addition to NO, hypoxia and tumour necrosis factor- $\alpha$ may be present in COPD as HO-1 inducers. However, the current results suggest that severe patients are unable to respond to these stimuli by increasing expression of HO- 1 .

A potential bias in this study performed on surgically resected specimens is that all control smokers had lung cancer whereas nine out of 11 severe COPD had not, and the presence of cancer itself may have influenced the results. There are no studies on HO-1 expression and lung cancer, while upregulation of iNOS was reported in patients with primary lung cancer [38]. If this is the case, the differences in iNOS expression would be even greater between two better matched groups of patients. Another potential bias is that, in LVRS, the surgeon selects the worst part of the lung, which might exaggerate pathological findings with respect to functional classification of the disease. No obvious differences were detected in the amount of tissue available for histological analysis (length of alveolar walls and number of alveolar macrophages) and in the counts of immunoreactivity between the two severe COPD patients with lung cancer and the remaining nine who had LVRS. However, the need for alveolar wall integrity for reliable cell counts might have prevented the evaluation of some parts of tissue from LVRS not suitable for analysis.

In conclusion, the current study showed that two enzymes that are inducible in response to oxidative stress in chronic obstructive pulmonary disease localise in different cell types of peripheral lung. Immunoreactivity for haem oxygenase-1 is mainly detected in alveolar macrophages, whereas immunoreactivity for inducible nitric oxide synthase is localised in type 2 pneumocytes. The results suggest that these enzymes may have a different role in the lung defence and that imbalance between haem oxygenase- 1 and inducible nitric oxide synthase may be linked with the development of severe impairment in chronic obstructive pulmonary disease patients.

\footnotetext{
Acknowledgements. The writers thank A. Baritussio for the kind gift of antibody to surfactant protein-B, and G. Fulgeri for secretarial assistance.
}

\section{References}

1. Rahman I, MacNee W. Oxidative stress and regulation of glutathione in lung inflammation. Eur Respir $J$ 2000; 16: 534-554.

2. Saetta M, Turato G, Maestrelli P, Mapp CE, Fabbri LM. Cellular and structural bases of chronic obstructive pulmonary disease. Am J Respir Crit Care Med 2001; 163: 1304-1309.

3. Choi AMK, Alam J. Heme oxygenase-1: function, regulation, and implication of a novel stress-inducible protein in oxidant-induced lung injury. Am J Respir Cell Mol Biol 1996; 15: 9-19.

4. Maines MD. Heme oxygenase: function, multiplicity, regulatory mechanisms and clinical applications. FASEB J 1988; 2: 2557-2568.

5. Maestrelli $\mathrm{P}$, El Messlemani A, De Fina O, et al. Increased expression of heme oxygenase (HO)-1 in alveolar spaces and HO-2 in alveolar walls of smokers. Am J Respir Crit Care Med 2001; 164: 1508-1513. 
6. Van der Vliet A, Eiserich JP, Shigenaga MK, Cross CE. Reactive nitrogen species and tyrosine nitration in the respiratory tract. Am J Respir Crit Care Med 1999; 160: 1-9.

7. Lakari E, Soini Y, Saily M, Koistinen P, Paakko P, Kinnula VL. Inducible nitric oxide synthase, but not xanthine oxidase, is highly expressed in interstitial pneumonias and granulomatous diseases of human lung. Am J Clin Pathol 2002; 117: 132-142.

8. Ichinose M, Sugiura H, Yamagata S, Koarai A, Shirato K. Increase in reactive nitrogen species production in chronic obstructive pulmonary disease airways. Am J Respir Crit Care Med 2000; 162: 701-706.

9. Rutgers SR, van der Mark TW, Coers W, et al. Markers of nitric oxide metabolism in sputum and exhaled air are not increased in chronic obstructive pulmonary disease. Thorax 1999; 54: 576-580.

10. Quanjer PhH, Tammeling GJ, Cotes JE, Pedersen OF, Peslin $\mathrm{R}$, Yernault J-C. Lung volumes and forced ventilatory flows. Eur Respir J 1993; 6: Suppl. 16, 5-40.

11. Lung function testing: Selection of reference values and interpretative strategies. American Thoracic Society. Am Rev Respir Dis 1991; 144: 1202-1218.

12. Miniati M, Filippi E, Falaschi F, et al. Radiologic evaluation of emphysema in patients with chronic obstructive pulmonary disease: chest radiography versus high resolution computed tomography. Am J Respir Crit Care Med 1995; 151: 1359-1367.

13. Turato G, Zuin R, Miniati M, et al. Airway inflammation in severe chronic obstructive pulmonary disease. Am J Respir Crit Care Med 2002; 166: 105-110.

14. Baritussio A, Alberti A, Quaglino D, et al. SP-A, SP-B, and SP-C in surfactant subtypes around birth: reexamination of alveolar life cycle of surfactant. Am J Physiol (Lung Cell Mol Physiol) 1994; 266: L436-L447.

15. Chinn S. Repeatability and methods comparison. Thorax 1991; 46: $454-456$.

16. National Institutes of Health. Global initiative for Chronic Obstructive Lung Disease. Publication no. 2701. 2001. Bethesda, MD, National Institutes of Health.

17. Da Silva JL, Morishita T, Escalante B, et al. Dual role of heme oxygenase in epithelial cell injury: contrasting effects of short-term and long-term exposure to oxidant stress. $J$ Lab Clin Med 1996; 128: 290-296.

18. Kharitonov SA, Yates D, Robbins RA, Logan-Sinclair R, Shinebourne EA, Barnes PJ. Increased nitric oxide in exhaled air of asthmatic patients. Lancet 1994; 343: 133-135.

19. Hanafy KA, Krumenacker JS, Murad F. NO, nitrotyrosine, and cyclic GMP in signal transduction. Med Sci Monit 2001; 7: 801-819.

20. Dennery PA, Spitz DR, Yang G, et al. Oxygen toxicity and iron accumulation in the lungs of mice lacking heme oxygenase-2. J Clin Invest 1998; 101: 1001-1011.

21. Lakari E, Pylkas P, Pietarinen-Runtti P, Paakko P, Soini Y, Kinnula VL. Expression and regulation of heme oxygenase 1 in healthy human lung and interstitial lung disorders. Hum Pathol 2001; 32: 1257-1263.

22. Lim S, Groneberg D, Fischer A, et al. Expression of heme oxygenase isoenzymes 1 and 2 in normal and asthmatic airways. Am J Respir Crit Care Med 2000; 162: 1912-1918.

23. Yamada N, Yamaya M, Okinaga S, et al. Microsatellite polymorphism in the heme oxygenase-1 gene promoter is associated with susceptibility to emphysema. Am J Hum Genet 2000; 66: 187-195.

24. Wright JL, Jeng AY, Battistini B. Effect of ECE and NEP inhibition on cigarette smoke-induced cell proliferation in the rat lung. Inhal Toxicol 2001; 13: 497-511.

25. Jeffery PK. Remodeling in asthma and chronic obstructive lung disease. Am J Respir Crit Care Med 2001; 164: s28-s38.

26. Guo FH, De Raeve HR, Rice TW. Continous nitric oxide synthase by inducible nitric oxide synthase in normal airway epithelium in vivo. Proc Natl Acad Sci USA 1995; 92: 7809-7813.

27. Saleh D, Ernst P, Lim S. Increased expression of the potent oxidant peroxinitrite in the airways of asthmatic patients is associated with induction of nitric oxide synthase: effect of inhaled glucocortocoid. FASEB J 1998; 12: 929-937.

28. Saleh D, Barnes PJ, Giaid A. Increased production of the potent oxidant peroxynitrite in the lungs of patients with idiopathic pulmonary fibrosis. Am J Respir Crit Care Med 1997; 155: 1763-1769.

29. Schroeder RA, Ewing CA, Sitzmann JV, Kuo PC. Pulmonary expression of iNOS and HO-1 protein upregulated in a rat model of prehepatic portal hypertension. Dig Dis Sci 2000; 45: 2405-2410.

30. Sherman TS, Chen Z, Yuhanna IS, Lau KS, Margraf LR, Shaul PW. Nitric oxide synthase isoform expression in the developing lung epithelium. Am J Physiol 1999; 276: L383-L390.

31. Punjabi CJ, Laskin JD, Pendino KJ, Goller NL, Durham SK, Laskin DL. Production of nitric oxide by rat type II pneumocytes: increased expression of inducible nitric oxide synthase following inhalation of a pulmonary irritant. $\mathrm{Am}$ J Respir Cell Mol Biol 1994; 11: 165-172.

32. Toga $\mathrm{H}$, Tobe $\mathrm{T}$, Ueda $\mathrm{Y}$, et al. Inducible nitric oxide synthase expression and nuclear factor kappa B activation in alveolar type cells in lung injury. Exp Lung Res 2001; 27: 485-504.

33. Retamales I, Elliott WM, Meshi B, et al. Amplification of inflammation in emphysema and its association with latent adenoviral infection. Am J Respir Crit Care Med 2001; 164: 469-473.

34. Corradi M, Majori M, Cacciani GC, Consigli GF, de' Munari E, Pesci A. Increased exhaled nitric oxide in patients with stable chronic obstructive pulmonary disease. Thorax 1999; 54: $572-575$.

35. Kanazawa H, Shoji S, Hirata K. Role of endogenous nitric oxide in airway obstruction in smokers. Chest 1996; 110: 927-929.

36. Turcanu V, Dhouib M, Poindron P. Nitric oxide synthase inhibition by heme oxygenase decreases macrophage nitric oxide dependent cytotoxicity: a negative feedback mechanism for the regulation of nitric oxide production. Res Immunol 1998; 149: 741-744.

37. Bouton C, Demple B. Nitric oxide inducible expression of heme oxygenase-1 in human cells. Translation independent stabilisation of the mRNA and evidence for direct action of nitric oxide. J Biol Chem 2000; 275: 32688-32693.

38. Liu CY, Wang CH, Chen TC, Lin HC, Yu CT, Kuo HP. Increased level of exhaled nitric oxide and up-regulation of inducible nitric oxide synthase in patients with primary lung cancer. Br J Cancer 1998; 78: 534-541. 